\title{
Activation of FoxO1/SIRT1/RANKL/OPG pathway may underlie the therapeutic effects of resveratrol on aging-dependent male osteoporosis
}

\author{
Omnia Ameen ${ }^{1}$, Rania I. Yassien ${ }^{2}$ and Yahya M. Naguib ${ }^{1,3^{*}}$ (D)
}

\begin{abstract}
Background: Age-dependent male osteoporosis remains a poorly studied medical problem despite its significance. It is estimated that at least 1 of 5 men will suffer from osteoporotic consequences. Given that multiple mechanisms are involved in the process of senescence, much attention has been given to compounds with polymodal actions. To challenge such a health problem, we tested here the therapeutic potential of resveratrol in male osteoporosis. We also studied the possible molecular mechanisms that may underlie resveratrol effects.

Methods: Thirty male Wistar albino rats were used in the present study. Rats were divided (10/group) into: control (3-4 months old weighing 150-200 g receiving vehicle), aged (18-20 months old, weighing 350-400 g and receiving vehicle), and resveratrol treated aged (18-20 months old, weighing 350-400 $\mathrm{g}$ and receiving resveratrol $20 \mathrm{mg} / \mathrm{kg} /$ day for 6 weeks) groups. Assessment of serum calcium, phosphate, bone specific alkaline phosphatase, inflammatory cytokines, oxidative stress markers, and rat femur gene expression of FoxO1, SIRT1, RANKL and OPG proteins was carried out. Histopathological assessment of different levels of rat femur was also performed.

Results: Age-dependent osteoporosis resulted in significant increase in serum levels of phosphate, bone specific alkaline phosphatase, hsCRP, IL-1 $\beta$, IL-6, TNF-a, MDA, NO, and RANKL gene expression. However, there was significant decrease in serum level of GSH, and gene expression of FoxO1, SIRT1 and OPG. Osteoporotic changes were seen in femur epiphysis, metaphysis and diaphysis. Resveratrol restored significantly age-dependent osteoporotic changes.

Conclusion: We concluded that resveratrol can play an important role in the prevention of male osteoporosis. Resveratrol can counter the molecular changes in male osteoporosis via anti-inflammatory, anti-oxidant and gene modifying effects.
\end{abstract}

Keywords: Male osteoporosois, Type II osteoporosis, Aging, Resveratrol, FoxO1, SIRT1, RANKL, OPG

\footnotetext{
* Correspondence: yahya.naguib@med.menofia.edu.eg

${ }^{1}$ Clinical Physiology Department, Faculty of Medicine, Menoufia University, Menoufia, Egypt

${ }^{3}$ Physiology Department, College of Medicine and Medical Sciences, Arabian Gulf University, Manama, Bahrain

Full list of author information is available at the end of the article
}

(c) The Author(s). 2020 Open Access This article is licensed under a Creative Commons Attribution 4.0 International License, which permits use, sharing, adaptation, distribution and reproduction in any medium or format, as long as you give appropriate credit to the original author(s) and the source, provide a link to the Creative Commons licence, and indicate if changes were made. The images or other third party material in this article are included in the article's Creative Commons licence, unless indicated otherwise in a credit line to the material. If material is not included in the article's Creative Commons licence and your intended use is not permitted by statutory regulation or exceeds the permitted use, you will need to obtain permission directly from the copyright holder. To view a copy of this licence, visit http://creativecommons.org/licenses/by/4.0/. The Creative Commons Public Domain Dedication waiver (http://creativecommons.org/publicdomain/zero/1.0/) applies to the data made available in this article, unless otherwise stated in a credit line to the data. 


\section{Background}

Osteoporosis is a prevalent skeletal disease in elderly which is characterized by progressive decrease in bone mass and increase in risk of fractures [1]. Although osteoporosis represents a major health and societal burden for both men and women, only a minority of men are screened for osteoporosis or treated for fracture prevention [2]. Osteoporotic fractures represent a major public health problem worldwide because of the associated morbidity, mortality and costs. The financial burden of osteoporotic fractures includes both direct (hospital acute care, in-hospital rehabilitation, outpatient services, long term nursing care), as well as indirect (co-morbid conditions) costs which may constitutes up to $75 \%$ of the overall healthcare cost of osteoporotic fractures. Nevertheless, some costs remain difficult to quantify, such as the deterioration of the patient quality of life, or the time spent by the family members taking care of the patient $[3,4]$. Traditionally considered as a disease of aging women, osteoporosis is becoming an increasingly important male health problem with one in three fragility fractures after the age of 50 years occurring in men [5]. Almost 30\% of hip fractures occur in men, and mortality risk after a hip or femoral fractures is higher in men than women [6]. Greater frailty may partly explain the increased fracture-related morbidity and mortality in men [7].

Bone is a dynamic and highly active tissue that undergoes a remodelling process throughout life via the coupled action of bone-resorbing cells (osteoclasts) and bone-forming cells (osteoblasts) [8]. The main principle of bone remodelling is to restore microdamage, adapt the skeleton to mechanical loading and maintain calcium and phosphorus homeostasis [9]. Bone homeostasis is achieved by an extremely coordinated communication between osteoblasts and osteoclasts. Generally, there are two cytokines that are produced largely by bone marrow stromal cells and osteoblasts and are essential for osteoclast viability: macrophage colony-stimulating factor (MCSF), and receptor activator of nuclear factor-kappa $B$ ligand (RANKL). RANKL stimulate osteoclast differentiation and activation, and inhibit osteoclast apoptosis [10]. These processes are antagonized by osteoprotegerin (OPG), a natural decoy receptor of RANKL which is mainly secreted by stromal cells and osteoblasts $[9,10]$.

It is well accepted that there are two distinct types of osteoporosis: postmenopausal (type I), and senile (type II) osteoporosis. Type II senile osteoporosis was generally attributed to the aging processes such as osteoblast dysfunction [10]. Unlike postmenopausal osteoporosis which involves mainly trabecular bone and is manifested clinically by fractures of the distal radius and vertebrae, aging-dependent osteoporosis involves both trabecular and cortical bone with characteristic hip fractures in addition to vertebral fractures [11]. Aging is generally associated with a progressive pro-inflammatory status, a phenomenon referred to as "inflammaging"; there is an increasing body of evidence that pro-resorptive cytokines, such as interleukin (IL)-1, IL-6 and tumour necrosis factor-alpha (TNF- $\alpha$ ) could be potentialy mediating age-dependent osteoporosis [12]. IL-1 production is increased in estrogen-deficient model systems [13]. In addition, the bone resorptive effects of TNF- $\alpha$ are well documented [14]. Several studies indicate that IL-6 plays a key role in mediating bone loss following estrogen deficiency [15]. Another key element in the skeletal deterioration associated with aging is the progressive free radical damage resulting from oxidative stress. The levels of reactive oxygen species (ROS) increase in bone with age and sex steroid deficiency [16]. The administration of antioxidants inhibits osteoblast and osteocyte apoptosis in the bone of ovariectomized or aged mice, denoting that oxidative stress may decrease osteoblast and osteocyte lifespan at the cellular level [16]. Oxidative stress may inhibit osteoblast formation. In fact, the attenuation of the Wnt signalling pathway that is critical for osteoblastogenesis by oxidative stress is mediated by the FoxOs transcription factors [17].

Several in vitro and in vivo studies have shown beneficial effects of resveratrol in osteoporosis. In vitro studies indicated that resveratrol was able to directly stimulate osteoblast proliferation and differentiation, inhibit formation and promoted its apoptosis of osteoclasts [18]. In vivo studies revealed that resveratrol was able to promote bone mineral density and inhibit bone loss in ovariectomized rats [19], in young rats under tail suspension [20], and in old rats under hind limb suspension [21]. Resveratrol has been shown to improve the bone mechanical tests in type II osteoporosis [8]. Nevertheless, the anti-osteoporotic effects of resveratrol have been poorly investigated in aging males. Accordingly, this study was designed to evaluate the therapeutic effects and the possible underlying mechanisms of resveratrol on type II osteoporosis in old male rats.

\section{Methods}

All experiments were conducted in adherence to the Guiding Principles in the Use and Care of Animals published by the National Institutes of Health (NIH Publication No 85-23, Revised 1996). Animal care and use were approved by the Faculty of Medicine Menoufia University Ethics Committee.

\section{Animals}

Thirty male Wistar rats were obtained from a local animal providing facility to be used in the present study. Rats were allowed to acclimatize for 10 days before the start experiments. Rats were given free access to normal 
chow diet and water in an air-conditioned room with a $12 \mathrm{~h}$ light-dark cycles. At the end of the study, rats were scarified by cervical dislocation.

\section{Experimental design}

After acclimatization, rats were divided into the following groups (10 rats per group): control group (3-4 months old weighing $150-200 \mathrm{~g}$ ), aged group (18-20 months old, weight 350-400 g), and resveratrol treated aged group (18-20 months old, weight $350-400$ g). Rats in the resveratrol treated aged group received resveratrol $(20 \mathrm{mg} / \mathrm{kg} /$ day for 6 weeks, Sigma-Aldrich Co., Mo, USA) via oral gavage, while those in the control and aged groups received equal amount of the vehicle $(0.9 \%$ $\mathrm{NaCl}$ ) via the same route.

\section{Blood sample collection}

At the end of experiments after 6 weeks, rats were fasted overnight and anaesthetised by sodium thiopental (STP, $60 \mathrm{mg} / \mathrm{kg}$ intraperitoneal injection). Blood was collected via cardiac puncture. Blood samples were left for $30 \mathrm{~min}$ at room temperature to allow for proper coagulation. Blood samples were then centrifuged at $2000 \mathrm{rpm}$ for 10 min and the serum was separated and collected. Serum samples were stored at $-20^{\circ} \mathrm{C}$ for further investigations.

\section{Biochemical analysis}

Serum levels of different biomarkers were detected by either quantitative sandwich enzyme immunoassay (ELISA) or colorimetric methods. Interleukin 6 (IL-6), interleukin $1 \beta$ (IL-1 $\beta$ ) and tumour necrosis factor alpha (TNF- $\alpha$ ) (Quantikine ELISA, R\&D Systems Inc., MN, USA), nitric oxide (NO) (QuantiChrom ${ }^{\mathrm{Tx}}$, BioAssay Systems, USA), high sensitivity $\mathrm{C}$ reactive protein (hsCRP) and bone specific alkaline phosphatase (BALP) (MyBioSource Inc., San Diego, CA, USA) were determined by ELISA technique using an automatic optical reader (SUNRISE Touchscreen, TECHAN, Salzburg, Austria). Glutathione (GSH) and malondialdehyde (MDA) (QuantiChrom $^{\text {tm }}$, BioAssay Systems, USA), calcium and phosphorus (ELITech, France) were determined by routine kinetic and fixed rate colorimetric methods on a Jenway Genova autoanalyser (UK).

\section{Analysis of gene expression quantitative RT-PCR (qRT- PCR)}

To evaluate the effects of aging and or resveratrol treatment on the studied groups, we examined the mRNA expression levels of forkhead box protein O1 (FoxO1), sirtuin 1 (SIRT1), receptor activator of nuclear factorkappa B ligand (RANKL), and osteoprotegerin (OPG) regulatory genes via real time quantitative reverse transcription-polymerase chain reaction (RT-PCR) assay as described previously [22-25]. Total RNA was extracted following grounding frozen femur bone specimens using TRI reagent (Sigma-Aldrich, UK). Reverse transcription of femur RNA was then performed using the high capacity RNA-to-cDNA kit (Applied Biosystems, CA, USA). Subsequently, the generated cDNA was used to measure mRNA expression for the selected genes. Gene specific primers were designed using Primer Express Software version 2.0 (Applied Biosystems, USA). Glyceraldehyde 3-phosphate dehydrogenase (GAPDH) was used as the housekeeping control gene (Table 1). RT- PCR assays were performed in duplicate for all target and housekeeping genes using Applied Biosystems 7500 FAST 96-well PCR machine (USA). With GAPDH serving as the endogenous control, relative mRNA expression of the gene of interest was calculated using the comparative $\mathrm{Ct}(2-\Delta \mathrm{Ct})$ method. Data were expressed as a ratio (target gene/GAPDH), and were shown as the mean \pm standard error of mean of at least three independent experiments.

\section{Haematoxylin and eosin (H\&E) stain}

At the end of the experiment, the right femur of every rat was dissected and processed for histopathology examination. The excised parts were longitudinally cut at the level of the metaphysis, while they were cut transversely at the epiphysis and the diaphysis levels. Cut bones were fixed for 2 days in neutral buffered formaldehyde, then they were decalcified using the chelating agent ethylenediaminetetraacetic acid (EDTA) in its disodium salt form. The chelating solution was prepared from $5.5 \mathrm{~g}$ EDTA, $90 \mathrm{ml}$ distilled water, and $10 \mathrm{ml}$ formalin. The decalcification period was 4 weeks, and the solutions were changed daily. The decalcifying solution volume was always maintained approximately 30-50 times the volume of the tissue. Decalcified bones were then dehydrated in ascending grades of alcohol, cleared in xylene, and impregnated in paraplast for $3 \mathrm{~h}$ in an oven at $58^{\circ} \mathrm{C}$. Thereafter, decalcified bones were embedded in paraplast. At a thickness of $7 \mathrm{~mm}$, serial sections

Table 1 Primers used for measuring the expression of FoxO1, SIRT, RANKL and OPG genes

\begin{tabular}{lll}
\hline FoxO1 & Forward & CACCTTGCTATTCGTTGC \\
& Reverse & CTGTCCTGAAGTGTCTGC \\
SIRT1 & Forward & AGA AACAATTCCTCCACCTGA \\
& Reverse & GCTTGGTGGTTCTGAAAGG \\
RANKL & Forward & GACAGGCACGGACT CGTA \\
& Reverse & CGCTCATGCTAGTC GTCTA \\
OPG & Forward & TGGCACACAGTGATGAATGCG \\
& Reverse & GCTGGAAAGTTGCTCTTGCG \\
GAPDH & Forward & TGCACCACCAACTGCTTAGC \\
& Reverse & GGCATGGACTGTGGTCATGAG \\
\hline
\end{tabular}


were cut, stained with $\mathrm{H} \& \mathrm{E}$ and examined under a light microscope [26].

\section{Statistical analysis}

Analysis of Variances (ANOVA) with Tukey's post hoc tests were used for statistical analysis of the data using Origin $^{\circ}$ software. Results were expressed as mean \pm standard error (SE), and $p$ values $<0.05$ were considered significant.

\section{Results}

Serum calcium level showed insignificant difference between the aged and control rats $(12.97 \pm 0.8$ vs $14.1 \pm$ $0.44 \mathrm{mg} / \mathrm{dl}$ ). However, serum calcium level was significantly lower in resveratrol treated aged group when compared to the control group $(11.75 \pm 0.59 \mathrm{mg} / \mathrm{dl})$, while it remained insignificantly different when compared to the aged rats (Fig. 1a). Serum phosphate level was significantly higher in the aged group when compared to the control group (6.4 \pm 0.79 vs $3.33 \pm 0.29$ $\mathrm{mg} / \mathrm{dl}$ ). Serum phosphate level was significantly lower in resveratrol treated aged group when compared to the aged group $(3.18 \pm 0.22 \mathrm{mg} / \mathrm{dl})$, but was insignificantly different when compared to the control rats (Fig. 1b). Serum bone specific alkaline phosphatase was significantly higher in the aged group when compared to the control group $(772.33 \pm 32.68$ vs $163.67 \pm 18.59 \mathrm{U} / \mathrm{dl})$. Serum bone specific alkaline phosphatase level was significantly lower in resveratrol treated aged group when compared to the aged group $(463.1 \pm 56.6 \mathrm{U} / \mathrm{dl})$, but it was still significantly higher than the corresponding value in the control group (Fig. 1c).

The histological examination showed sections from different levels of the rat femur stained with H\&E. The epiphysis in the control group demonstrated normal histological appearance showing irregular cancellous bone with bone marrow spaces in between. Sections from the epiphysis in the aged group revealed loss of

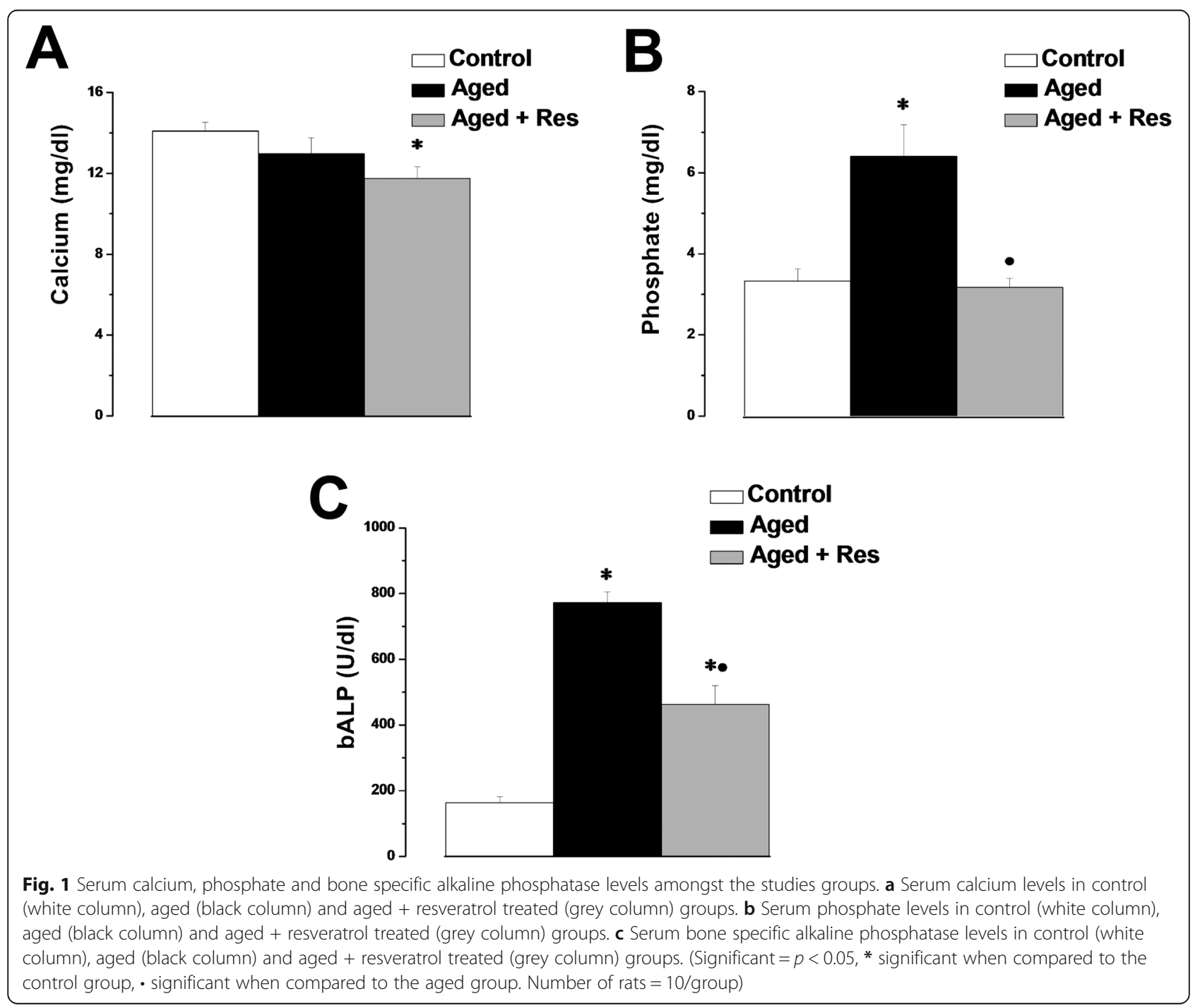


normal architecture of the cancellous bone with thin disconnected widely separated trabeculae. Some trabeculae showed refractile areas indicating bone loss and necrosis. Some eroded areas were seen on the bone surface. Moreover, there were numerous fat cells within the widening adjacent bone marrow. Sections from the epiphysis in the resveratrol treated aged rats showed apparently normal bone trabeculae, however, few areas of broken bone with erosion cavity could be seen in this group. Sections from the metaphysis of the control group demonstrated regularly arranged cell columns in characteristic zones: resting, proliferating, hypertrophic, and calcified zones, followed by the ossification zone. Sections from the metaphysis of the aged rats showed irregularly arranged columns of cells in the proliferating zone, with many degenerated cells and decreased basophilia of the matrix compared with the control group. In resveratrol treated aged group, the epiphyseal plate showed more regularity of cell columns in the proliferating zone with more basophilia of the matrix when compared to the aged non-treated rats. Sections from the diaphysis of the control group demonstrated the classical appearance of compact bone with many Haversian systems and covered by periosteum. Sections from the diaphysis of the aged group revealed that some osteocytes had wide lacunae, with an apparent decrease in the number of osteocytes when compared to the control group. Woven bone appeared with uneven staining of bone matrix with indistinct cement lines. Several resorption cavities were also seen within the matrix. Areas of palely stained osteoid matrix were noticed as well. Many multinucleated osteoclasts housed within erosion cavities could be seen. Sections from the diaphysis of the resveratrol treated aged rats showed marked improvement in bone structure when compared to the aged non-treated group. Nevertheless, some irregularly arranged osteocytes were seen within the bone matrix. However, the osteoclasts were fewer than those seen in the aged nontreated group (Figs. 2 and 3). The periosteum in the aged non-treated rats showed marked thinning, especially the fibrous layer, while it almost retained its normal thickness in the resveratrol treated group. Narrowing of Haversian canal was evident in the aged non-treated group, while it was almost normal in the resveratrol treated group. An area of faintly stained bone matrix with no osteocytes surrounded by osteoclasts in Howship's lacunae was seen in the aged group. Small erosion cavities could still be seen in the resveratrol treated group (Fig. 4).

The serum level of the pro-inflammatory biomarkers hsCRP, IL- $1 \beta$, IL- 6 and TNF- $\alpha$ were significantly higher in the aged rats $(13.67 \pm 0.88,332.38 \pm 3.8,13.3 \pm 1.58$, $1106.18 \pm 52.8 \mathrm{ng} / \mathrm{ml}$ respectively), when compared to the corresponding values in the control group (4.1 \pm
$0.76,263.37 \pm 6.78,4.83 \pm 0.66,694.07 \pm 7.12 \mathrm{ng} / \mathrm{ml}$ respectively). Treatment with resveratrol resulted in significant decrease in hsCRP, IL- $1 \beta$, IL- 6 and TNF- $\alpha$ levels $(7.23 \pm 0.47,284.5 \pm 2.19,7.57 \pm 0.35,872.8 \pm 32.29 \mathrm{ng} / \mathrm{ml}$ respectively) when compared to the aged group, however, their levels remained significantly higher when compared to the control group (Fig. 5a, b, c and d).

There was significant decrease in the GSH level in the aged group when compared to the control group (2.27 \pm 0.23 vs $4.3 \pm 0.12 \mathrm{uM} / \mathrm{ml}$ ). Serum GSH level was significantly higher in resveratrol treated aged group when compared to the aged group $(3.03 \pm 0.11 \mathrm{uM} / \mathrm{ml})$, while it was still significantly lower when compared to the control rats (Fig. 6a). Expectedly, there was a significant increase in the MDA and NO levels in the aged group $(12.57 \pm 0.99 \mathrm{nM} / \mathrm{ml}$ and $234.78 \pm 5.97 \mathrm{uM} / \mathrm{l}$ respectively), when compared to the corresponding values in the control group $(5.1 \pm 0.38 \mathrm{nM} / \mathrm{ml}$ and $166.67 \pm 3.44$ $\mathrm{uM} / \mathrm{l}$ respectively). MDA and NO levels in the resveratrol treated group $(8.78 \pm 0.5 \mathrm{nM} / \mathrm{ml}$ and $204.07 \pm 6.42$ $\mathrm{uM} / \mathrm{l}$ respectively) were significantly lower when compared to the aged group, however, they were significantly higher than the corresponding values in the control group (Fig. 6b and c).

Expression of the FoxO1, SIRT1 and OPG genes $(0.73 \pm 0.02,0.61 \pm 0.04$ and $0.58 \pm 0.03$ respectively), was significantly lower in the aged rats when compared to the control group (1). FoxO1, SIRT1 and OPG gene expression was significantly higher in the resveratrol treated rats $(1.05 \pm 0.09,0.98 \pm 0.07$ and $1.09 \pm 0.08$ respectively), when compared to the aged group. RANKL gene expression was significantly up-regulated in the aged group when compared to the control group (1.84 \pm 0.12 vs 1). RANKL gene expression was significantly lower in the resveratrol treated rats $(1.13 \pm 0.27)$, when compared to the aged group. There was insignificant difference in FoxO1, SIRT1, OPG and RANKL gene expression between resveratrol treated aged group and the control group (Fig. 7).

\section{Discussion}

Aging is a progressive decline of the natural homeostatic mechanisms, leading to deterioration of tissues and organs functions with subsequent deleterious health outcomes [8]. Osteoporosis is a skeletal disorder characterized by low bone mass, structural weakening, decreased bone strength and increased risk of fractures resulting in rapid growth osteoporosis related morbidity amongst the elderly [27]. Osteoporosis represents a major health and societal burden in men as well as in women, nevertheless, not often men are screened for osteoporosis [2]. Consequently, finding new therapeutic approaches to slow down age-related osteoporosis has been a target for researchers. Rat model of male 


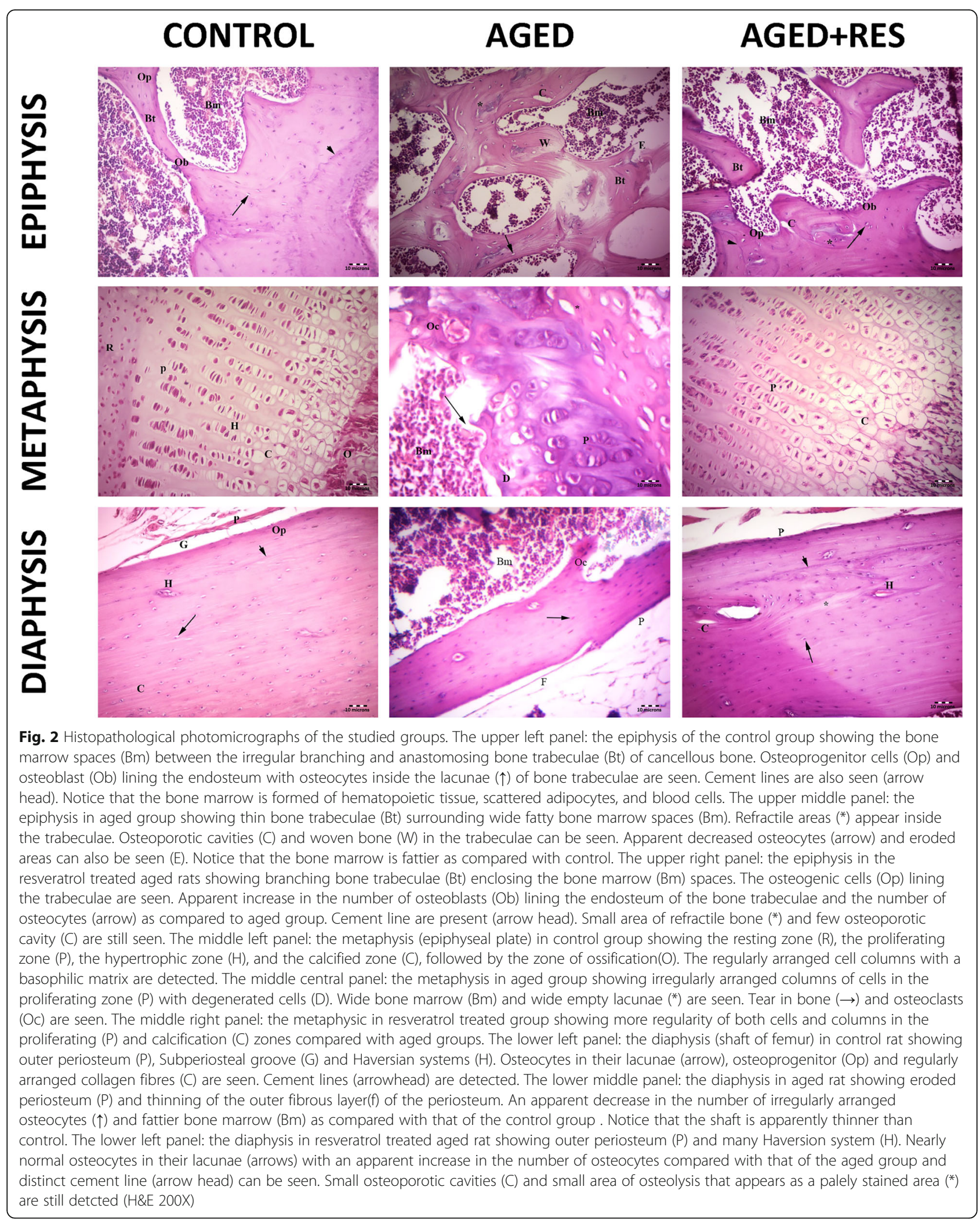




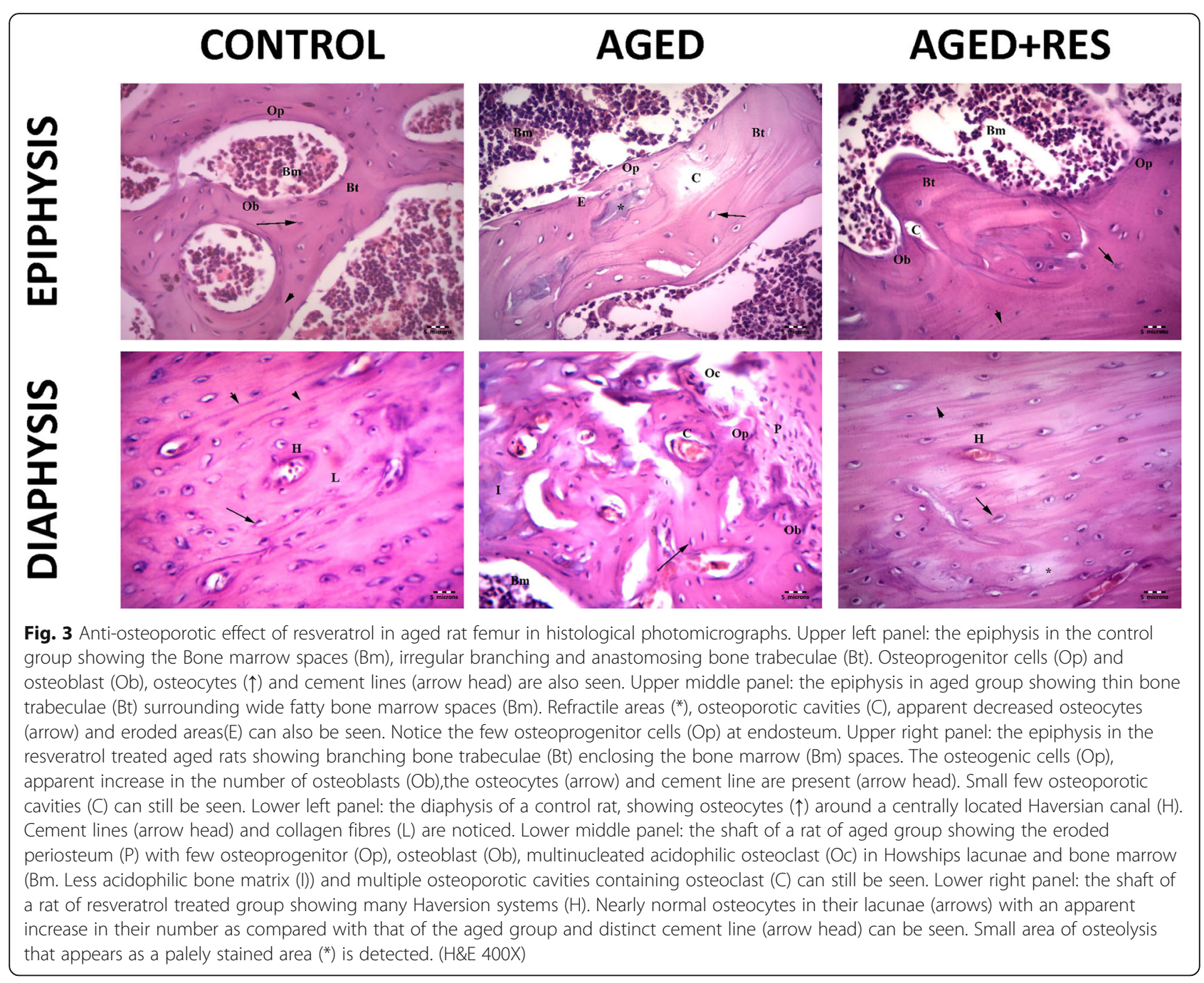

osteoporosis help in better understanding of the disease, and therefore, test for possible therapies. It has been reported that 9 months old male rats started showing agerelated bone loss [28]. Rats used in the present study are comparable to 55-60 years old male humans [29]. Resveratrol is a polyphenolic compound naturally present in grapes, cranberries, and nuts. There is a growing body of evidence that resveratrol may be an effective therapeutic agent for age-related degenerative diseases including osteoporosis [30]. Resveratrol is able to target cytomembranes, intracellular receptors, signalling molecules, enzymes, oxidative system, DNA repair system, and transcription factors [31]. We demonstrated here a potential therapeutic role of resveratrol on male osteoporosis. We also elucidated that resveratrol antiosteoporotic effects may involve the employment of FoxO1/SIRT1/RANKL/OPG pathway.

Serum BALP, phosphate and calcium are classical bone turnover markers. In the present study the mean values of serum bone specific alkaline phosphatase and phosphate were significantly higher in the aged group when compared with the control group. Similar results were reported previously [32, 33]. BALP is an important enzyme for osteoid formation and mineralization, and can be used as an index for the rate of overall bone turnover presenting the relation between bone resorption, bone formation and bone mineralization; the high bone turnover rate in osteoporosis is associated with increased serum BALP [32]. Another important indicator of the rate of bone remodelling is the concentration of serum phosphate. Disproportionate increase in bone resorption will lead to a higher plasma phosphate concentration, whereas increased bone mineralization causes lower serum phosphate level [34]. Resveratrol treated aged rats had significantly lower serum BALP and phosphate values when compared to aged non-treated rats. Evidence has shown that resveratrol has the capability of inhibiting osteoclasts differentiation, activity and accordingly bone turnover [18]. The inhibitory effect of resveratrol on osteoclast differentiation was associated with 


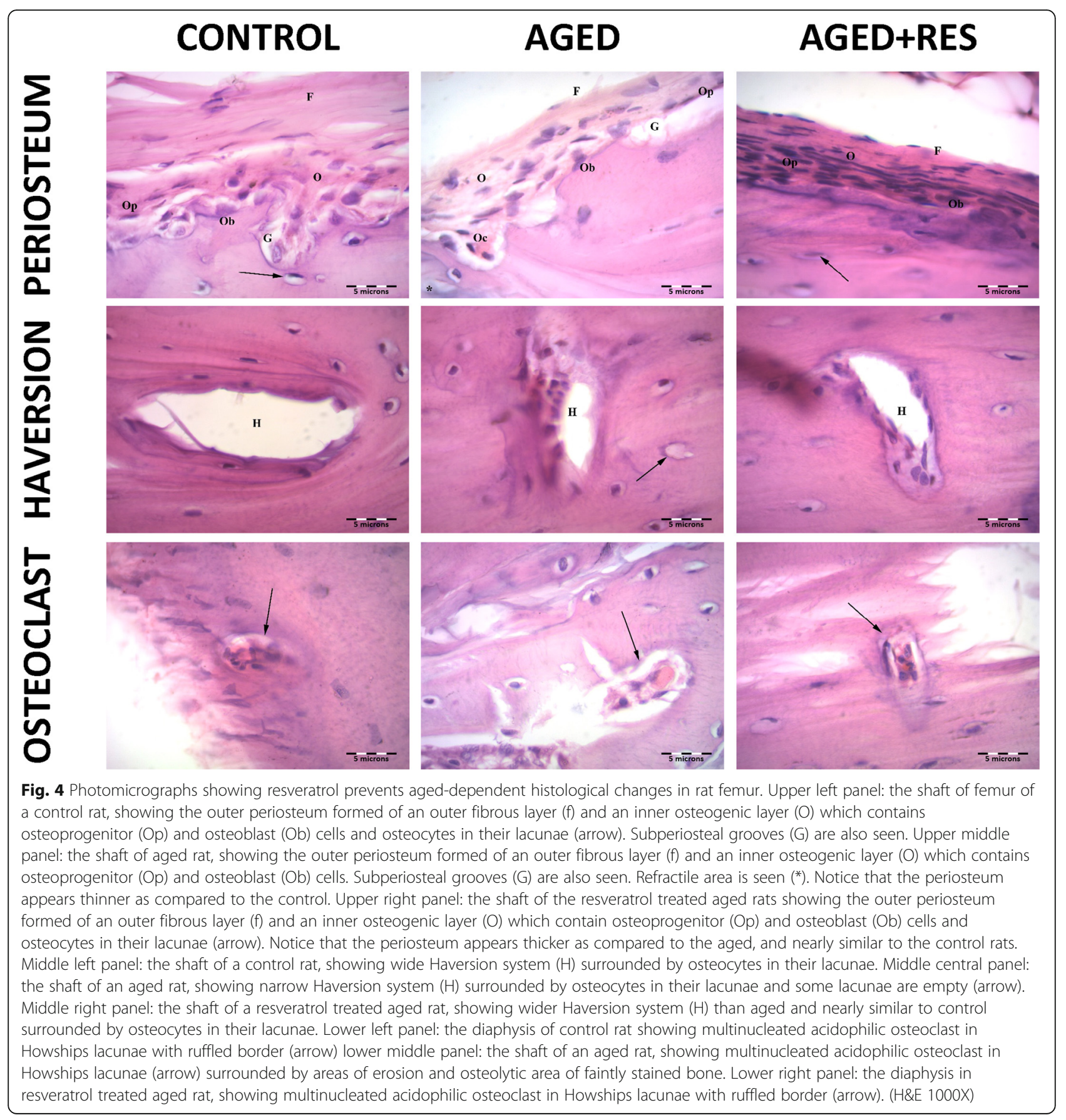

decreased serum BALP [35]. The mean value of serum calcium was insignificantly different in the aged group when compared to the corresponding value in the control group. This result was in agreement with previously published reports [32]. Nevertheless, serum calcium was suggested to be decreased in postmenopausal women with osteoporosis [33]. In our hands, administration of resveratrol in aged male rats led to decrement in serum calcium level reflecting a possible role of resveratrol in enhancing bone calcium deposition. Resveratrol has been shown to stimulate osteoblast activity, and therefore, increase bone mineralization [36]. In support to our results, it was reported that a transient decrease in serum calcium typically occurred within the first few weeks after administration of a potent anti-resorptive agents [37].

In the present work, histopathological findings demonstrated clearly the age-dependent osteoporotic changes in male rat femurs. Changes included significant decrease in the thickness of cortical and cancellous bone, 


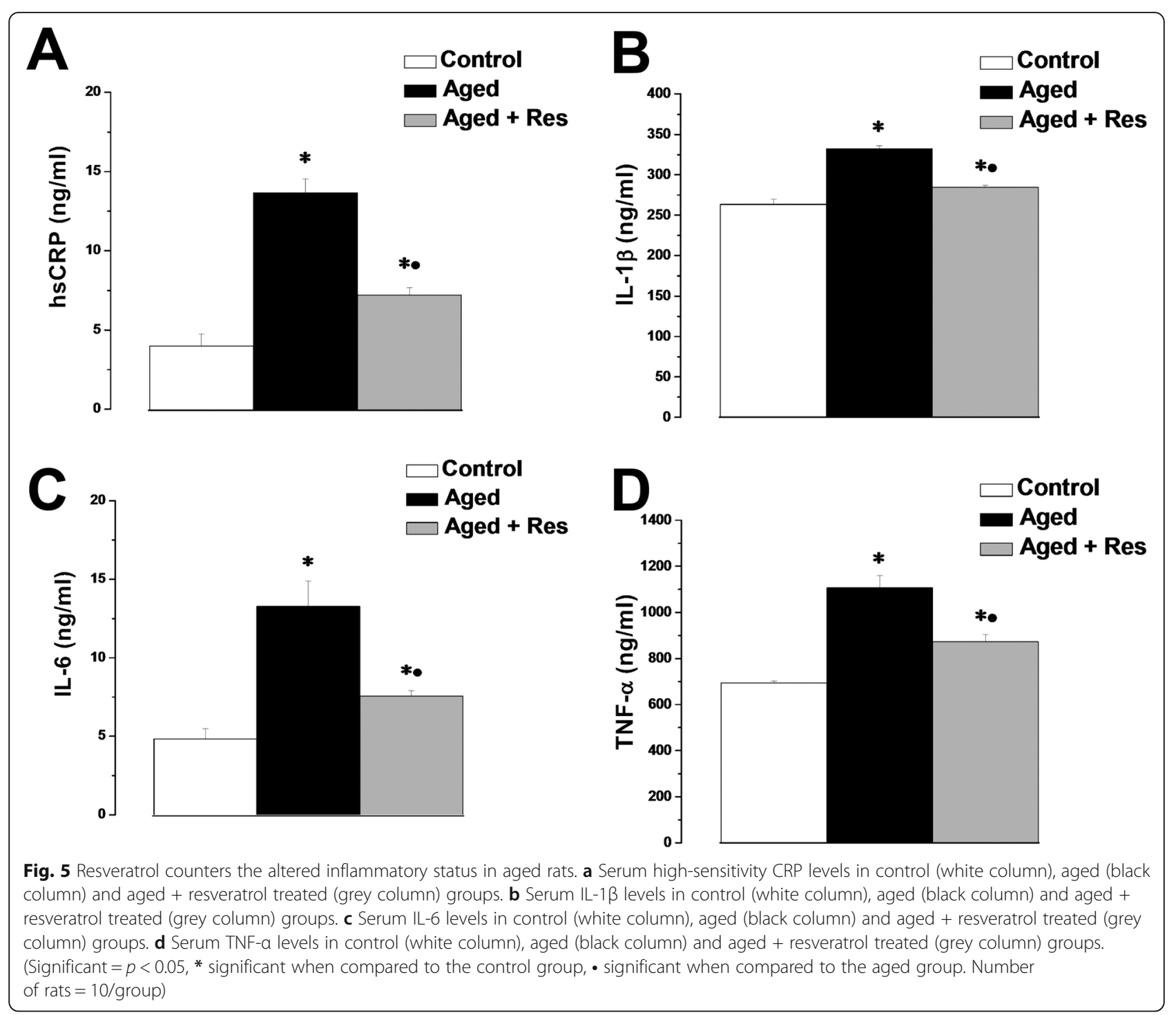

widely separated bone trabeculae, osteoporotic cavities, irregularly eroded endosteal surfaces and woven bone in the trabeculae, and apparent decrease in number of osteocytes. Bone loss in osteoporosis could be initiated by the increase in depth of erosion cavities causing disruption of the trabeculae and perforation, leading eventually to conversion of the trabecular plates to widely separated rods and bars [38, 39]. The formation of erosion cavities with active brush border may result from the increase in the number of active osteoclasts, with subsequent bone resorption and rarefaction [40]. A possible relationship between abnormal lipid metabolism and osteonecrosis may coexist based on the presence of excess fat cells in the bone marrow of the aged rats [41]. Resveratrol substantially improved agedependent histopathological changes in aged rats. Indeed resveratrol was reported to improve the microstructure of aged male rat femurs [8].
In the present study the serum level of the proinflammatory markers hsCRP, IL- $1 \beta$, IL- 6 and TNF- $\alpha$ was significantly higher in the aged group when compared to the corresponding values in the control group. Aging is associated with chronic low-grade increase in the circulating levels of inflammatory markers, which may be associated with low bone density [42, 43]. During the aging process, tissues release cytokines such as IL$1 \beta$, IL-6, and TNF- $\alpha$, proteins such CRP, and proinflammatory transcription factors such as the nuclear factor kappa B $(\mathrm{NF} \kappa \mathrm{B})$. The circulating inflammatory mediators have been implicated in the pathogenesis and progression of tissue alteration and failure in the elderly [24]. Pro-inflammatory cytokines might induce the formation of reactive oxygen species (ROS) which could trigger an inflammatory response through the activation of transcription factor NFKB [44]. NF- $\mathrm{KB}$ then translocates into the nucleus where it activates a variety of 


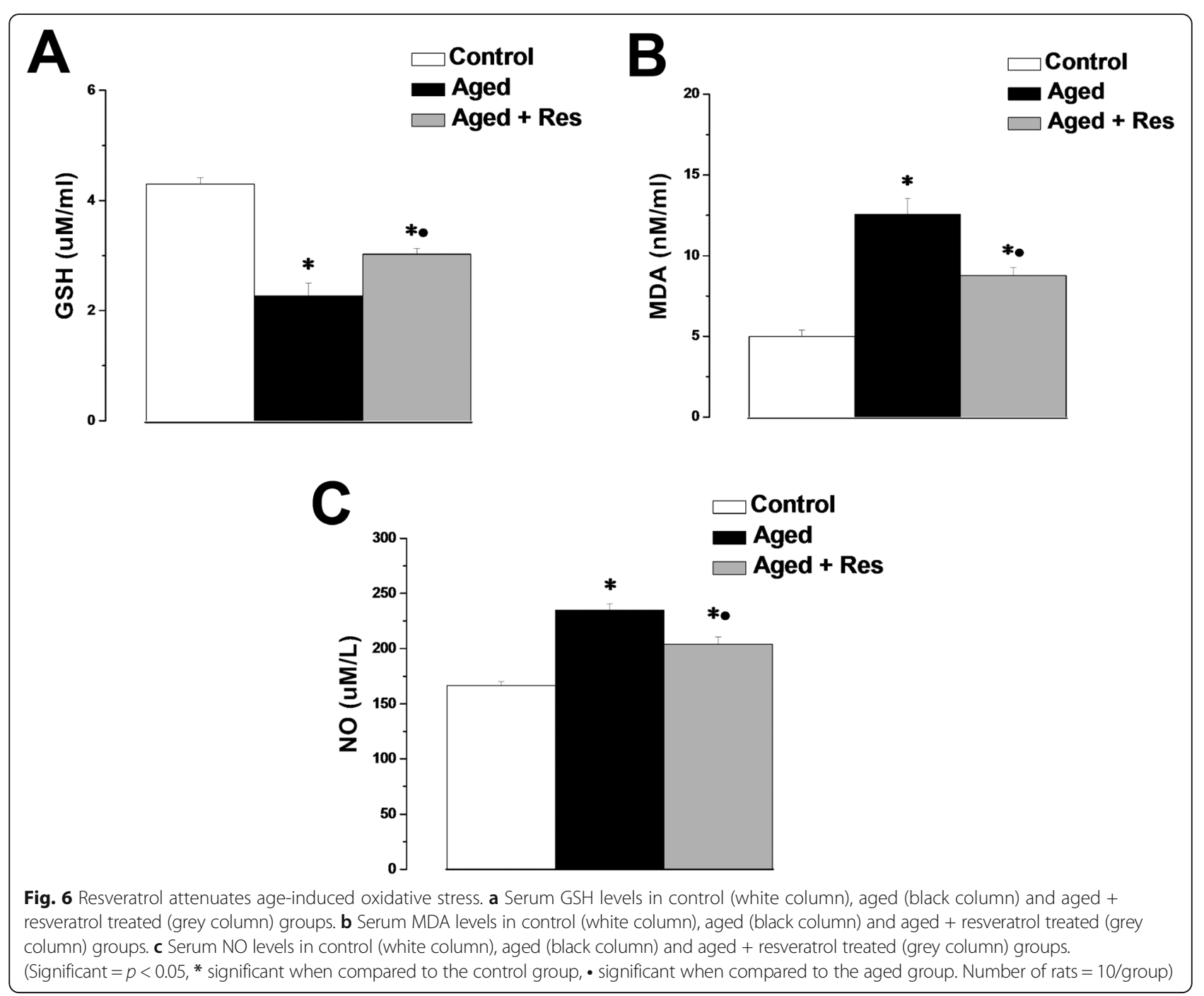

inflammatory genes such as inducible nitric oxide synthase (iNOS), COX-2, IL-1 $\beta$, IL-6, IL-8, TNF- $\alpha$ and monocyte chemoattractant protein-1[45]. Consecutively, IL- $1 \beta$ and TNF- $\alpha$ could activate NF- $\kappa B$ forming an amplifying feed-forward loop; a vicious cycle that may eventually lead to cell, tissue or organ dysfunction [8, 42]. Resveratrol has well proven anti-inflammatory activities. Resveratrol supplementation can directly suppress the release of the proinflammatory cytokines TNF- $\alpha$, IL- $1 \beta$, IL-6, IL-10, monocyte chemoattractant protein-1 (MCP$1)$, interferon alpha (IFN- $\alpha)$, and IFN- $\beta$ in a wide range of rodents tissues $[18,46]$.

The serum levels of MDA and NO in the present investigations were significantly higher, while GSH was significantly lower in the aged group when compared to the corresponding values in the control group. The administration of resveratrol significantly restored the redox balance. Age-dependent oxidative stress occurs when the production of ROS exceeds the antioxidant defence capacity [24]. ROS promotes lipid peroxidation, oxidation of proteins and nucleic acids, and structural alteration of the membranes resulting in cellular damage [47]. Oxidative stress alters bone remodelling process causing an imbalance between osteoclast and osteoblast activities. This can lead to metabolic bone diseases and contribute to the pathogenesis of osteoporosis [17]. Agedependent bone loss differs from estrogen-dependent osteoporosis in the progressive loss of osteoblasts activity rather than the enhanced osteoclast activity. The reduction in osteoblast activity during aging could be caused by an accumulation of adipocytes at the expense of osteoblasts in the bone marrow. Increased adipocytes in bone marrow may result in oxidative stress due to higher susceptibility to lipid peroxidation [48]. Oxidative stress stimulates osteoclastogenesis; significant increase in the number and activity of osteoclasts was observed when $\mathrm{H}_{2} \mathrm{O}_{2}$ was added to the cultures of human bone marrow mononuclear cells [44]. Furthermore, ROS 


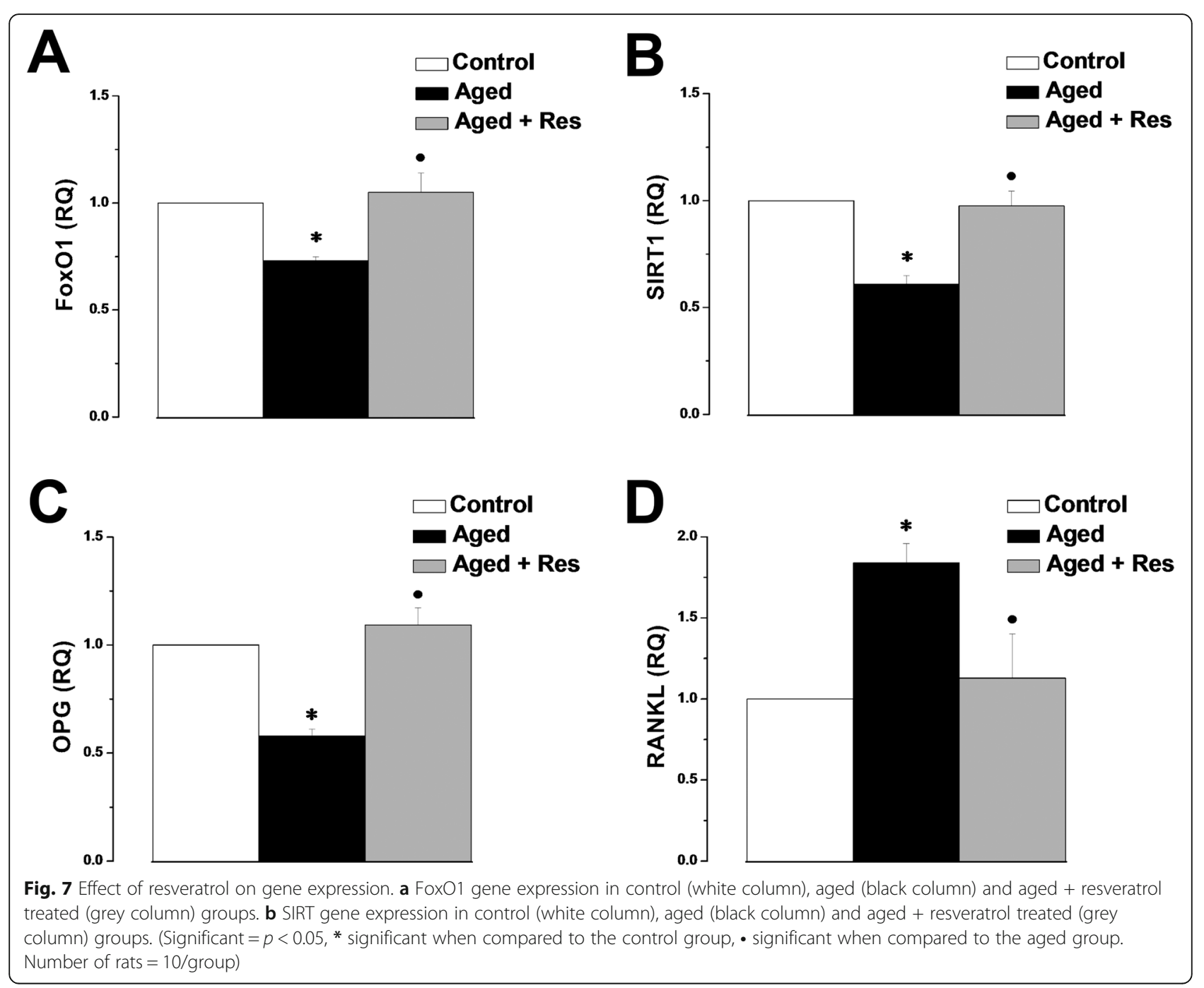

induce the apoptosis of osteoblasts and osteocytes, thus favouring osteoclastogenesis [49]. Excessive apoptosis of osteocytes is correlated to an increased oxidative status causing an imbalance in favour of osteoclastogenesis [50]. Several factors produced by osteoblasts and osteocytes, most importantly the ligand of receptor activator of NFkB (RANKL) and osteoprotegerin (OPG), regulate both osteoclasts and osteoblasts activities. RANKL is produced by osteoblasts and activates the differentiation and activity of osteoclasts by interacting with specific receptors in preostoeclasts and mediates osteoclastogenesis and bone resorption [47]. Also, RANKL promotes the accumulation of $\mathrm{H}_{2} \mathrm{O}_{2}$ in osteoclasts and in their progenitors, which in turn improves osteoclasts proliferation. Therefore, increased ROS level, particularly $\mathrm{H}_{2} \mathrm{O}_{2}$, is a critical regulatory step in osteoclastogenesis and bone resorption [51]. OPG, a soluble receptor capable of binding and blocking RANKL, is produced by the activation of the signalling pathway Wnt/ $\beta$ catenin resulting in inhibition of osteoclasts activity. Oxidative stress blocks the activation of osteoblasts and thus the production of OPG; enabling the action of RANKL to prevail with subsequent promotion of osteoclast differentiation and activity. The increase in RANKL/OPG ratio is, in fact, an index for the intensity of bone resorption [47]. Amongst all herbal medicines, recently termed natureceuticals, resveratrol health benefits have been well documented. Most of resveratrol therapeutic effects are owed to its antioxidant properties. It was reported earlier that resveratrol can act as a scavenger of superoxide and hydroxyl radicals, and peroxynitrite. Resveratrol was also reported to be capable of activating several antioxidant enzymes [52]. We could assume that the improvement in osteoporotic changes in our work could be partly due to the antioxidant properties of resveratrol.

It was important then to identify the possible molecular mechanisms that may underlie resveratrol effects on age-dependent osteoporosis in aged males. The real-time PCR results for the FoxO1, SIRT1 and OPG genes demonstrated a significant down-regulation of their gene 
expression in aged rats, while there was a significant upregulation of RANKL gene expression. Resveratrol treated rats showed up-regulation of the FoxO1, SIRT1 and OPG gene expression, with concomitant downregulation of RANKL.

SIRT1 is the first member of the Sirtuin protein family to be discovered. SIRT1is a longevity associated protein; activation of SIRT1 in mice was associated with a delay in the onset of many aging-related diseases, including osteoporosis [53]. Enzymes associated with SIRT1 are histone acetylation enzymes and, therefore, can regulate several molecules including NF- $\mathrm{kB}$, enabling SIRT1 to regulate inflammation [54]. It has been reported that resveratrol-mediated SIRT1 activation can inhibit the NF-kB signalling pathway promoting osteoblasts differentiation [35, 39, 48]. Additionally, resveratrol can elicit a SIRT1-dependent inhibition of osteoclastogenesis [55]. Human adult retinal pigment epithelial (RPE) cells pretreated with the SIRT1 activator SRT1720 showed abrogation of IL-8, IL-6 and MMP-9 expression [56]. The anti-apoptotic and anti-oxidant effects of resveratrol were abolished by SIRT1 knockdown in C2C12 myoblast cells; suggesting that SIRT1 is pivotal in mediating resveratrol-induced cell protecting effects [57]. SIRT1 siRNA blocked the anti-osteoporotic effect of resveratrol in ovariectomized rat model strengthening the assumption that resveratrol exerts its anti-osteoporotic action via SIRT1-NF-kB pathway [27, 35]. FoxO1, a member of the Forkhead box $\mathrm{O}$ family of proteins, is the most abundant isoform in osteoblasts. Accordingly, FoxO1 is thought to control bone formation through osteoblasts proliferation and differentiation, and redox balance [58]. FoxO1 can counteract the generation of ROS by overexpression of the antioxidant enzymes such as glutathione peroxidise and superoxide dismutase [59]. It has been reported that in hematopoietic stem cells FoxO1 reduces ROS by up-regulating the expression of antioxidant enzymes, whereas FoxO1 deletion led to an increase in osteoclast progenitors in the bone marrow [60]. FoxO1 is a target for SIRT1; SIRT1 appears to shift the FoxO1-dependent response towards the antioxidant activity and redox balance [57]. Receptor activator of nuclear factor- $\mathrm{kB}$ (RANK) is a member of the tumor necrosis factor family expressed by osteoclasts. The final common pathway in the regulation of bone resorption involves the interaction of RANK with its ligand (RANKL) [61]. Inhibiting RANKL significantly affects bone metabolism, and therefore, is a reasonable therapeutic strategy for the treatment of osteoporosis and other bone diseases characterized by increased bone turnover. OPG is the natural inhibitor of RANKL; Osteoporosis developed in OPG-deficient mice, while over-expression of OPG in mice inhibited osteoclastogenesis and improveded bone mass [62, 63]. Taken together, resveratrol seems to be able to shift the RANKL/OPG pathways toward osteobalstogenesis in age-dependent male osteoporosis.

\section{Conclusion}

The present study demonstrated that treatment with resveratrol could guard against age-dependent osteoporosis in males both on the functional and structural levels. By means of its versatile actions, resveratrol ameliorated the inflammatory and oxidative stress conditions commonly present with senescence, and therefore averted the ageinduced deleterious effects on the bone. The antiosteoporotic effect of resveratrol could be mediated, at least in part, by altering the FoxO1/SIRT1/RANKL/OPG pathway. We report here a novel effect and underlying mechanism of resveratrol on type II osteoporosis.

\section{Abbreviations}

BALP: Bone specific alkaline phosphatase; FoxO1: Forkhead box protein O1; GSH: Glutathione; hCRP: high sensitivity C reactive protein; IL: Interleukin; MCSF: Macrophage colony-stimulating factor; MDA: Malondialdehyde; NFkB: Nuclear factor kappa B; NO: Nitric oxide; OPG: Osteoprotegerin; ROS: Reactive oxygen species; RANKL: Receptor activator of nuclear factorkappa B ligand; SIRT1: Sirtuin 1; TNF-a: Tumour necrosis factor-alpha

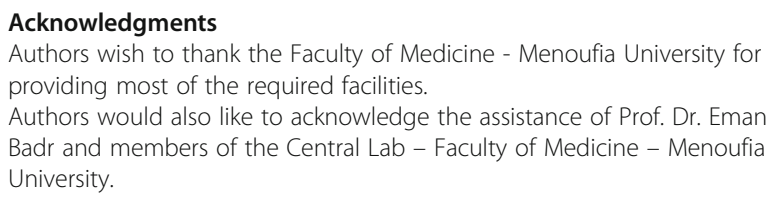

\section{Authors' contributions}

OA carried out the animal experiments and biochemical assays, and participated in the study design. RIY performed the histopathology studies. YMN carried out the PCR experiments, participated in the study design and coordination, analysed the results, performed the statistical analysis and drafted the manuscript. All authors have read and approved the final version of the manuscript.

\section{Funding}

This research did not receive any specific grant from funding agencies in the public, commercial, or not-for-profit sectors.

Availability of data and materials

Data supporting findings are presented within the manuscript.

Ethics approval and consent to participate

This study was approved by the Ethical Committee of the Faculty of Medicine, Menoufia University, Egypt.

\section{Consent for publication}

Not applicable.

\section{Competing interests}

No conflict of interests.

\section{Author details}

${ }^{1}$ Clinical Physiology Department, Faculty of Medicine, Menoufia University, Menoufia, Egypt. ${ }^{2}$ Histology and Cell Biology Department, Faculty of Medicine, Menoufia University, Menoufia, Egypt. ${ }^{3}$ Physiology Department, College of Medicine and Medical Sciences, Arabian Gulf University, Manama, Bahrain. 
Received: 4 March 2020 Accepted: 1 June 2020

Published online: 12 June 2020

\section{References}

1. $\mathrm{NIH}$. NIH consensus development panel on osteoporosis prevention, diagnosis, and therapy, March 7-29, 2000: highlights of the conference. Southern Med J. 2001:94(6):569-73.

2. Gennari L, Bilezikian JP. New and developing pharmacotherapy for osteoporosis in men. Exp Opin Pharmacother. 2018;19(3):253-64.

3. Roche JJ, Wenn RT, Sahota O, Moran CG. Effect of comorbidities and postoperative complications on mortality after hip fracture in elderly people: prospective observational cohort study. BMJ. 2005;331(7529):1374.

4. Orsini LS, Rousculp MD, Long SR, Wang S. Health care utilization and expenditures in the United States: a study of osteoporosis-related fractures. Osteoporos Int. 2005;16(4):359-71.

5. Johnell O, Kanis JA. An estimate of the worldwide prevalence and disability associated with osteoporotic fractures. Osteoporos Int. 2006;17(12):1726-33.

6. D'Amelio P, Isaia GC. Male Osteoporosis in the Elderly. Int J Endocrinol. 2015:2015:907689.

7. Laurent M, Gielen E, Claessens F, Boonen S, Vanderschueren D. Osteoporosis in older men: recent advances in pathophysiology and treatment. Best Pract Res. 2013:27(4):527-39.

8. Tresguerres IF, Tamimi F, Eimar H, Barralet J, Torres JS, Blanco L, Tresguerres JA. Resveratrol as anti-aging therapy for age-related bone loss. Rejuvenat Res. 2014;17(5):439-45

9. Sommerfeldt DW, Rubin CT. Biology of bone and how it orchestrates the form and function of the skeleton. Eur Spine J. 2001;10(Suppl 2):S86-95.

10. Pietschmann P, Rauner M, Sipos W, Kerschan-Schindl K. Osteoporosis: an age-related and gender-specific disease--a mini-review. Gerontology. 2009; 55(1):3-12.

11. Riggs BL, Khosla S, Melton $L J$ 3rd. A unitary model for involutional osteoporosis: estrogen deficiency causes both type I and type || osteoporosis in postmenopausal women and contributes to bone loss in aging men. J Bone Miner Res. 1998;13(5):763-73.

12. Franceschi $C$, Bonafe $M$, Valensin S, Olivieri F, De Luca M, Ottaviani E, De Benedictis G. Inflamm-aging. An evolutionary perspective on immunosenescence. Ann New York Acad Sci. 2000;908:244-54.

13. Tanaka S, Takahashi N, Udagawa N, Tamura T, Akatsu T, Stanley ER, Kurokawa T, Suda T. Macrophage colony-stimulating factor is indispensable for both proliferation and differentiation of osteoclast progenitors. J Clin Invest. 1993:91(1):257-63.

14. Kitazawa R, Kimble RB, Vannice $J$, Kung VT, Pacifici R. Interleukin-1 receptor antagonist and tumor necrosis factor binding protein decrease osteoclast formation and bone resorption in ovariectomized mice. J Clin Invest. 1994; 94(6):2397-406.

15. Jilka RL, Hangoc G, Girasole G, Passeri G, Williams DC, Abrams JS, Boyce B, Broxmeyer $\mathrm{H}$, Manolagas SC. Increased osteoclast development after estrogen loss: mediation by interleukin-6. Science. 1992;257(5066):88-91.

16. Jilka RL, Almeida M, Ambrogini E, Han L, Roberson PK, Weinstein RS, Manolagas SC. Decreased oxidative stress and greater bone anabolism in the aged, when compared to the young, murine skeleton with parathyroid hormone administration. Aging Cell. 2010;9(5):851-67.

17. Manolagas SC. From estrogen-centric to aging and oxidative stress: a revised perspective of the pathogenesis of osteoporosis. Endocrine Rev. 2010;31(3):266-300.

18. Shakibaei M, Shayan P, Busch F, Aldinger C, Buhrmann C, Lueders C, Mobasheri A. Resveratrol mediated modulation of Sirt-1/Runx2 promotes osteogenic differentiation of mesenchymal stem cells: potential role of Runx2 deacetylation. PloS one. 2012;7(4):e35712.

19. Zhao H, Li X, Li N, Liu T, Liu J, Li Z, Xiao H, Li J. Long-term resveratrol treatment prevents ovariectomy-induced osteopenia in rats without hyperplastic effects on the uterus. British J Nutr. 2014;111(5):836-46.

20. Habold C, Momken I, Ouadi A, Bekaert V, Brasse D. Effect of prior treatment with resveratrol on density and structure of rat long bones under tailsuspension. J Bone Mineral Metabol. 2011;29(1):15-22.

21. Durbin SM, Jackson JR, Ryan MJ, Gigliotti JC, Alway SE, Tou JC. Resveratrol supplementation preserves long bone mass, microstructure, and strength in hindlimb-suspended old male rats. J Bone Mineral Metabol. 2015;32(1):38-47.

22. El Agamy DF, Naquib YM. CoQ10 ameliorates monosodium glutamateinduced alteration in detrusor activity and responsiveness in rats via anti- inflammatory, anti-oxidant and channel inhibiting mechanisms. BMC Urol. 2019;19(1):103.

23. Lee AMC, Shandala T, Nguyen L, Muhlhausler BS, Chen K-M, Howe PR, Xian CJ. Effects of resveratrol supplementation on bone growth in young rats and microarchitecture and remodeling in ageing rats. Nutrients. 2014;6(12): 5871-87.

24. Motawea SM, Noreldin RI, Naguib YM. Potential therapeutic effects of endothelial cells trans-differentiated from Whartonâ $€^{\mathrm{TM}} \mathrm{S}$ Jelly-derived mesenchymal stem cells on altered vascular functions in aged diabetic rat model. Diabetol Metabol Syndrome. 2020;12(1):40.

25. Rizk NI, Rizk MS, Mohamed AS, Naguib YM. Attenuation of sleep deprivation dependent deterioration in male fertility parameters by vitamin C. Reprod Biol Endocrinol. 2020;18(1):2.

26. Goldschlager T, Abdelkader A, Kerr J, Boundy I, Jenkin G. Undecalcified bone preparation for histology, histomorphometry and fluorochrome analysis. J Visual Exp. 2010;35:1707.

27. Wang $X$, Chen L, Peng W. Protective effects of resveratrol on osteoporosis via activation of the SIRT1-NF-kappaB signaling pathway in rats. Exp Ther Med. 2017:14(5):5032-8.

28. Wang L, Banu J, McMahan CA, Kalu DN. Male rodent model of age-related bone loss in men. Bone. 2001:29(2):141-8.

29. Sengupta P. The laboratory rat: relating its age with human's. Int J Prevent Med. 2013:4(6):624-30.

30. Petrovski G, Gurusamy N, Das DK. Resveratrol in cardiovascular health and disease. Ann New York Acad Sci. 2011;1215:22-33.

31. Zhao L, Wang Y, Wang Z, Xu Z, Zhang Q, Yin M. Effects of dietary resveratrol on excess-iron-induced bone loss via antioxidative character. J Nutr Biochem. 2015;26(11):1174-82

32. Mukaiyama K, Kamimura M, Uchiyama S, Ikegami S, Nakamura Y, Kato H. Elevation of serum alkaline phosphatase (ALP) level in postmenopausal women is caused by high bone turnover. Aging Clin Exp Res. 2015;27:413-8.

33. Pardhe BD, Pathak S, Bhetwal A, Ghimire S, Shakya S, Khanal PR, Marahatta SB. Effect of age and estrogen on biochemical markers of bone turnover in postmenopausal women: a population-based study from Nepal. Int J Womens Health. 2017:9:781-8.

34. Penido MG, Alon US. Phosphate homeostasis and its role in bone health. Pediatr Nephrol. 2012;27(11):2039-48.

35. Feng J, Liu S, Ma S, Zhao J, Zhang W, Qi W, Cao P, Wang Z, Lei W. Protective effects of resveratrol on postmenopausal osteoporosis: regulation of SIRT1-NF-kappaB signaling pathway. Acta Biochim Biophys Sin (Shanghai). 2014;46(12):1024-33.

36. Ornstrup MJ, Harsløf T, Sørensen L, Stenkjær L, Langdahl BL, Pedersen SB. Resveratrol Increases Osteoblast Differentiation In Vitro Independently of Inflammation. Calcified Tissue Int. 2016;99:155-63.

37. Kostenuik PJ, Capparelli C, Morony S, Adamu S, Shimamoto G, Shen V, Lacey DL, Dunstan CR. OPG and PTH-(1-34) have additive effects on bone density and mechanical strength in osteopenic ovariectomized rats. Endocrinology. 2001;142(10):4295-304

38. Lau RY, Guo X. A review on current osteoporosis research: with special focus on disuse bone loss. J Osteoporosis. 2011;2011:6

39. Tou JC. Evaluating resveratrol as a therapeutic bone agent: preclinical evidence from rat models of osteoporosis. Ann New York Acad Sci. 2015; 1348:75-85.

40. Klein-Nulend J, van Oers RFM, Bakker AD, Bacabac RG. Bone cell mechanosensitivity, estrogen deficiency, and osteoporosis. J Biomech. 2014; 48(5):855-65.

41. Motomura G, Yamamoto T, Miyanishi K, Yamashita A, Sueishi K, Iwamoto Y. Bone marrow fat-cell enlargement in early steroid-induced osteonecrosis-a histomorphometric study of autopsy cases. Pathol Res Pract. 2005;200(11): 807-11.

42. Kireev RA, Tresguerres ACF, Garcia C, Ariznavarreta C, Vara E, Tresguerres JAF. Melatonin is able to prevent the liver of old castrated female rats from oxidative and pro-inflammatory damage. J Pineal Res. 2008;45:394-402.

43. Redlich K, Smolen JS. Inflammatory bone loss: pathogenesis and therapeutic intervention. Nat Rev Drug Discov. 2012;11:234.

44. Baek KH, Oh KW, Lee WY, Lee SS, Kim MK, Kwon HS, Rhee EJ, Han JH, Song $\mathrm{KH}$, Cha BY, et al. Association of Oxidative stress with postmenopausal Osteoporosis and the effects of hydrogen peroxide on osteoclast formation in human bone marrow cell cultures. Calcified Tissue Int. 2010;87:226-35.

45. Gloire G, Dejardin E, Piette J. Extending the nuclear roles of $\|^{\circ} \mathrm{B}$ kinase subunits. Biochem Pharmacol. 2006;72(9):1081-9. 
46. Bi XL, Yang JY, Dong YX, Wang JM, Cui YH, Ikeshima T, Zhao YQ, Wu CF. Resveratrol inhibits nitric oxide and TNF-Î \pm production by lipopolysaccharide-activated microglia. Int Immunopharmacol. 2005;5(1): 185-93.

47. Domazetovic V, Marcucci G, lantomasi T, Brandi ML, Vincenzini MT. Oxidative stress in bone remodeling: role of antioxidants. Clin Cases Mineral Bone Metabol. 2017;14(2):209-16.

48. Tou JC. Resveratrol supplementation affects bone acquisition and osteoporosis: Pre-clinical evidence toward translational diet therapy. Biochimica et Biophysica Acta Mol Basis Dis. 2015;1852(6):1186-94.

49. Jilka RL, Noble B, Weinstein RS. Osteocyte Apoptosis. Bone. 2013;54(2):264-71.

50. Fontani F, Marcucci G, lantomasi T, Brandi ML, Vincenzini MT. Glutathione, $\mathrm{N}$-acetylcysteine and Lipoic Acid Down-Regulate Starvation-Induced Apoptosis, RANKL/OPG Ratio and Sclerostin in Osteocytes: Involvement of JNK and ERK1/2 Signalling. Calcified Tissue Int. 2015;96:335-46.

51. Bartell SM, Kim H-N, Ambrogini E, Han L, lyer S, Serra Ucer S, Rabinovitch P, Jilka RL, Weinstein RS, Zhao H, et al. FoxO proteins restrain osteoclastogenesis and bone resorption by attenuating $\mathrm{H}(2) \mathrm{O}(2)$ accumulation. Nat Commun. 2014;5:3773.

52. Chin YT, Cheng GY, Shih YJ, Lin CY, Lin SJ, Lai HY, Whang-Peng J, Chiu HC, Lee SY, Fu E, et al. Therapeutic applications of resveratrol and its derivatives on periodontitis. Ann New York Acad Sci. 2017;1403(1):101-8.

53. Mercken EM, Mitchell SJ, Martin-Montalvo A, Minor RK, Almeida M, Gomes AP, Scheibye-Knudsen M, Palacios HH, Licata JJ, Zhang Y, et al. SRT2104 extends survival of male mice on a standard diet and preserves bone and muscle mass. Aging Cell. 2014;13(5):787-96.

54. Yang $H$, Zhang W, Pan H, Feldser HG, Lainez E, Miller C, Leung S, Zhong Z, Zhao H, Sweitzer S, et al. SIRT1 Activators Suppress Inflammatory Responses through Promotion of p65 Deacetylation and Inhibition of NF-1B Activity. PLoS One. 2012;7(9):e46364.

55. Titorencu I, Pruna V, Jinga W, Simionescu M. Osteoblast ontogeny and implications for bone pathology: an ovenview. Cell Tissue Res. 2014;355:23-33.

56. Cao L, Liu C, Wang F, Wang H. SIRT1 negatively regulates amyloid-betainduced inflammation via the NF-1º pathway. Brazil J Med Biol Res. 2013; 46(8):659-69.

57. Hori YS, Kuno A, Hosoda R, Horio Y. Regulation of FOXOs and p53 by SIRT1 modulators under oxidative stress. PLoS One. 2013;8(9):e73875.

58. Rached M-T, Kode A, Xu L, Yoshikawa Y, Paik J-H, DePinho RA, Kousteni S. FOXO1 is a positive regulator of bone formation by favoring protein synthesis and resistance to oxidative stress in osteoblasts. Cell Metab. 2010; 11(2)::147.

59. Feng J, Liu S, Ma S, Zhao J, Zhang W, Qi W, Cao P, Wang Z, Lei W. Protective effects of resveratrol on postmenopausal osteoporosis: regulation of SIRT1-NF-I'B signaling pathway. Acta Biochimica et Biophysica Sinica. 2018;46(12):1024-33.

60. Ambrogini E, Almeida M, Martin-Millan M, Paik JH, Depinho RA, Han L, Goellner J, Weinstein RS, Jilka RL, O'Brien CA, et al. FoxO-mediated defense against oxidative stress in osteoblasts is indispensable for skeletal homeostasis in mice. Cell Metab. 2010;11(2):136-46.

61. McClung M. Role of RANKL inhibition in osteoporosis. Arthritis Res Ther. 2007;9(Suppl 1):S3

62. Kong Y-Y, Feige U, Sarosi I, Bolon B, Tafuri A, Morony S, Capparelli C, Li J, Elliott R, McCabe $S$, et al. Activated T cells regulate bone loss and joint destruction in adjuvant arthritis through osteoprotegerin ligand. Nature. 1999;402:304.

63. Takayanagi H, lizuka H, Juji T, Nakagawa T, Yamamoto A, Miyazaki T, Koshihara Y, Oda H, Nakamura K, Tanaka S. Involvement of receptor activator of nuclear factor ${ }^{\circ} \mathrm{B}$ ligand/osteoclast differentiation factor in osteoclastogenesis from synoviocytes in rheumatoid arthritis. Arthritis Rheumatism. 2000;43:259-69.

\section{Publisher's Note}

Springer Nature remains neutral with regard to jurisdictional claims in published maps and institutional affiliations.

Ready to submit your research? Choose BMC and benefit from:

- fast, convenient online submission

- thorough peer review by experienced researchers in your field

- rapid publication on acceptance

- support for research data, including large and complex data types

- gold Open Access which fosters wider collaboration and increased citations

- maximum visibility for your research: over $100 \mathrm{M}$ website views per year

At BMC, research is always in progress.

Learn more biomedcentral.com/submissions 